\title{
Pyoderma gangrenosum in myelodysplasia and acute leukaemia
}

\author{
Peter Jacobs $^{1}$, S. Palmer ${ }^{2}$ and E.C. Gordon-Smith ${ }^{2}$
}

${ }^{I}$ The University of Cape Town Leukaemia Centre and the Department of Haematology, Groote Schuur Hospital, Observatory, 7925, Cape Town, South Africa and ${ }^{2}$ The Department of Haematology, Royal Postgraduate Medical School, London, UK.

\begin{abstract}
Summary: Pyoderma gangrenosum is a rare occurrence in patients with haematological malignancy. This characteristic but nonspecific inflammatory process with skin destruction occurred in 4 patients with myelodysplasia, in one with acute leukaemic transformation of myelofibrosis, and in de novo acute myeloblastic leukaemia in another. Clinically, the cutaneous lesion in these patients differed from that associated with inflammatory bowel disease, arthritis, or the idiopathic type of pyoderma gangrenosum by having the vesiculo-bullous borders. Histopathological differences were also evident since more superficial layers of the skin were involved in the ulceration than typically encountered in patients with non-malignant systemic disease.

Despite the less penetrating nature of this variant, treatment of the pyoderma gangrenosum is unsatisfactory and in the absence of effective therapy for the underlying disease, healing occurred only in the patient with acute leukaemia who achieved complete remission in response to chemotherapy.
\end{abstract}

\section{Introduction}

Pyoderma gangrenosum describes a nonspecific form of cutaneous ulceration that is progressive, begins as a tender erythematous nodule, then forms a pustule, followed by rapid central necrosis characterized by oedematous and dusky overhanging borders with a surrounding margin of erythema (Brunsting et al., 1930). The ulcers typically enlarge to exceed $10 \mathrm{~cm}$ in diameter, persist for weeks or months, and heal with scarring, often to recur over a period of years.

Although in many instances there is no clear association with any underlying systemic disease, giving rise to the concept of idiopathic pyoderma gangrenosum, the classical clinical association is with ulcerative colitis, where an incidence between $1 \%$ and $3 \%$ has been reported (Sloan et al., 1950; Perry \& Brunsting, 1957). Pyoderma gangrenosum may also be found with arthritis (Stolman et al., 1975; Holt, 1980 ), and in a number of less clearly defined disorders (Wolff \& Stingl, 1983).

Maldonada and his associates (1968) first reported the occurrence of this entity with leukaemia. Subsequently, an atypical variant was described in chronic granulocytic and myelomonocytic leukaemia, where

Correspondence: Professor P. Jacobs, F.R.C.P. (Edin), F.R.C.Path. (UK), Department of Haematology - Research Centre, University of Cape Town Medical School, Anzio Road, Observatory 7925, Cape Town, South Africa.

Accepted: 27 February 1985 the lesions were more superficial and their margins bullous (Perry \& Winkelmann, 1972). Further experience (Tay, 1973; Fayolle et al., 1974; Goldin, 1974; Lewis et al., 1978) has emphasized clinical differences between the typical lesions of the idiopathic type, those associated with inflammatory bowel disease or arthritis, and the ulceration found together with haematological malignancy. In the former examples this destructive skin lesion extends into and involves the reticular layer of the dermis and the subcutis, but usually spares the subcutaneous tissue. In contrast, the skin pathology found with myelodysplasia or leukaemia is more superficial and has vesiculo-bullous borders. No specific causative agent has been isolated and while pathergy, which describes the phenomenon of trivial trauma provoking new lesions or aggravating existing ones (Wolff \& Stingl, 1983), has been reported, there is generally spontaneous healing in parallel with resolution or control of the underlying disorder. In patients with the myelodysplastic syndrome, relentless progression of the induration and the ulcer occur, providing an ideal nidus for secondary infection, leading to septicaemia and death. In those patients where leukaemia responds to treatment, complete healing of the ulcer may occur. These points are emphasized by our experience with 4 patients having preleukaemia and 2 with acute leukaemia, all having pyoderma gangrenosum. 


\section{Case histories}

\section{Case 1}

A 39 year old male developed severe anaemia in October 1977 when a bone marrow biopsy showed dyserythropoiesis and a mild increase in blast cells. Over the next $2 \mathrm{y}$ he was maintained on intermittent red cell transfusions. Two weeks after a transfusion, in October 1979, the patient noticed pain in his left calf. The following day a bruise developed over the left ankle. Over the next $10 \mathrm{~d}$ this slowly enlarged to form a superficial haematoma. Surgical drainage was attempted but this was followed by the development of a large ulcer. He was transferred to Hammersmith Hospital in December 1979. At that time he had a large necrotic ulcer measuring $11 \mathrm{~cm} \times 8 \mathrm{~cm}$ over the left medial malleolus. The edge of the ulcer showed the typical rolled edge and blue-grey colour of pyoderma gangrenosum. The patient was febrile and had a palpable spleen $4 \mathrm{~cm}$ below the costal margin.

Haematology results showed haemoglobin $8.3 \mathrm{~g} / \mathrm{dl}$, white blood count $3.3 \times 10^{9} / 1$, and platelets $15 \times 10^{9} / 1$. Differential count showed $8 \%$ blast cells, $8 \%$ myelocytes, $4 \%$ metamyelocytes, $44 \%$ neutrophils, $27 \%$ lymphocytes and $9 \%$ monocytes. The neutrophils were abnormal, with marked hypogranularity and abnormal segmentation. The bone marrow was hypercellular with abnormal granulopoiesis, dyserythropoiesis and scanty mononuclear megakaryocytes. Blast cells constituted $8 \%$ of the differential count. Bone marrow chromosomes showed a consistent pseudodiploid abnormality. A diagnosis of myelodysplastic syndrome without leukaemic change was made.

Initial treatment with prednisone at $60 \mathrm{mg} /$ day resulted in a good response with decreased erythema and some healing. However, as the dose of prednisone was redueed relapse of the pyoderma oecurred. A month after commencement of prednisone the dose had been reduced to $20 \mathrm{mg} /$ day and at that time the patient developed swelling in his right scrotum. Initially, this was thought to be an epididymo-orchitis. However, there was no response to antibiotics and the lesion rapidly advanced to pyoderma gangrenosum. This eventually resulted in a scrotal-rectal fistula, the patient dying soon after from secondary infection. No specific pathogens were cultured from the early lesions. During his stay in hospital there was no evidence of development of an overt leukaemia.

\section{Case 2}

A 58 year old man first presented in July 1979 with symptoms of aching limbs. He was noted to be anorexic, and subsequent blood test showed a pancytopenia. Over the next 9 months he required red cell transfusion every 4 weeks. Corticosteroids were given but this made no difference to his pancytopenia. In March 1980, on a dose of $15 \mathrm{mg}$ prednisone a day he developed a painful haematoma on his left leg. This eventually broke down and developed into a large chronic ulcer. When seen at Hammersmith Hospital he had pyoderma gangrenosum on his shin, measuring $15 \mathrm{~cm}$ in diameter. He had no lymphadenopathy and his spleen was not palpable. Haematology results showed haemoglobin $14.4 \mathrm{~g} / \mathrm{dl}$, white blood count $0.9 \times 10^{9} / 1$ with $18 \%$ neutrophils, and platelets $22 \times 10^{9} / 1$.

The bone marrow aspirate and trephine biopsy were both hypocellular with marked depression of granulopoiesis and erythropoiesis. Blast cells constituted $20 \%$ of the differential count. The appearances were those of a refractory anaemia with increased blast cells. His subsequent course was one of gradual deterioration. He became progressively more pancytopenic and suffered recurrent infections. The pyoderma gangrenosum failed to heal but had not extended at the time of his death from septicaemia. The patient did not progress to overt leukaemia.

\section{Case 3}

A 78 year old white man presented in February 1980 short of breath with haemorrhagic lesions over the scrotum. Examination revealed bruises over the arms and legs and $3 \mathrm{~cm}$ hepatosplenomegaly Haemoglobin was $6.9 \mathrm{~g} / \mathrm{dl}$, MCV $105 \mathrm{fl}$, white blood count of $2.3 \times 10^{9} / 1$ with $22 \%$ neutrophils, $45 \%$ lymphocytes, $3 \%$ eosinophils, $5 \%$ monocytes, $20 \%$ hypogranular myelocytes and promyelocytes, with $5 \%$ myeloblasts. Platelets were $58 \times 10^{9} / 1$ and there were 5 nucleated red cells for every 100 white cells in the differential count. Bone marrow aspiration and trephine biopsy showed hypercellularity, megaloblastic haematopoiesis, and $10 \%$ atypical myeloblasts.

In view of the patient's age and unwillingness to undergo any form of chemotherapy he was treated with blood transfusions. Quality of life remained excellent and peripheral blast count varied between $4 \%$ and $36 \%$. Five months after diagnosis a hot tender swelling developed on the right thigh following very minor injury. This became a red indurated area of cellulitis that formed an abscess which spontaneously ruptured. Culture of the sero-sanguineous material was negative. The centre of this cutaneous lesion became a black necrotic eschar measuring $10 \mathrm{~cm}$ in diameter and the edges were rolled and purple in colour. Biopsy showed nonspecific inflammatory changes. Culture of curettings and skin biopsy grew a staphylococcus resistant to cloxacillin, two strains of bacteroides, and a scanty growth of Klebsiella and Clostridium welchii. Shortly after this a second lesion 
developed on the left lower chest and biopsy again showed nonspecific inflammatory infiltrate only; cultures were negative.

The clinical picture of both lesions was considered to be that of pyoderma gangrenosum and the patient treated on $1 \mathrm{mg} / \mathrm{kg}$ of prednisone orally each day, red cell transfusions as necessary to maintain haemoglobin between 10 and $12 \mathrm{~g} / \mathrm{dl}$, and no specific therapy for the preleukaemia. Despite regular dressings the lesions, which remained clean, failed to granulate and progressed gradually. Nine months after diagnosis the blast count gradually rose to over $70 \%$, thrombocytopenia became more severe and the patient developed pneumonia and septicaemia, and died in November 1980.

\section{Case 4}

A 60 year old man presented in November 1976 for a routine medical examination. Haemoglobin was $11.9 \mathrm{~g} / \mathrm{dl}$, MCV $95 \mathrm{fl}$, white blood count $1.3 \times 10^{9} / 1$. Myelodysplastic features were present in the granulocytic series. Bone marrow was hypercellular with increase in ringed sideroblasts, monocytes were prominent, and hypogranularity was evident in the myeloid series. A diagnosis of preleukaemia was made and the patient observed without therapy. In February of 1978 he again sought medical attention because of boils. At this time haemoglobin was $8.3 \mathrm{~g} / \mathrm{dl}$, white cell count and morphology unchanged, but platelets were $53 \times 10^{9} / 1$. In June, one of the boils had become indurated and formed a mass in his left calf, measuring $8 \times 10 \mathrm{~cm}$ with a large surrounding erythematous area. A clinical diagnosis of cellulitis was made and the patient treated with antibiotics. There was a slow improvement in the erythema, but localization and spontaneous rupture with central breakdown and extensive tissue necrosis occurred within 4 weeks. By September of that year 3 further similar lesions had occurred and with the clinical condition relatively stable, the patient was managed on transfusions only. In March of the following year the patient presented again with a large perianal swelling and a mass in the left quadriceps. The perianal lesion resolved slowly but that in the thigh broke down, draining serosanguineous fluid which was repeatedly negative on blood culture. Within 2 months further lesions had developed and the patient admitted with septicaemic shock and died.

Terminally, granulocytes were absent from the peripheral circulation. Bone marrow examination was unchanged from the initial study and showed no leukaemic transformation.

\section{Case 5}

The patient, a 44 year old woman, first presented in
August 1980 with spontaneous bruising and tiredness. Bone marrow aspiration was unsuccessful but the bone marrow trephine biopsy showed malignant myelofibrosis with marked increase in reticulin and collagen, megakaryocytic proliferation and increased blast cells. From August 1980 to March 1981 she was given intermittent blood transfusion and remained reasonably well. In March 1981 she was readmitted to hospital with symptoms of tiredness and bleeding. Haematology results at that time showed haemoglobin $5 \mathrm{~g} / \mathrm{dl}$, white blood count $0.4 \times 10^{9} / 1$, and platelets $12 \times 10^{9} / 1$. She was given systemic antibiotics for continuing fever and commenced on prednisone. While in hospital she developed severe pain in both legs. Within $24 \mathrm{~h}$ she developed two areas of erythema and bruising on her lower limbs. In April 1981 she was transferred to Hammersmith Hospital. On both legs there were single raised tender purple nodules covered by shiny smooth skin. The larger nodule showed early bullous formation and measured $5 \mathrm{~cm} \times 4 \mathrm{~cm}$ and over the next $3 \mathrm{~d}$ ulcerated to show the typical features of a superficial bullous pyoderma gangrenosum. No specific pathogens were cultured from the lesion.

Haematology on admission showed haemoglobin $10.3 \mathrm{~g} / \mathrm{dl}$, white blood count $1.3 \times 10^{9} / 1$, and platelets $7 \times 10^{9} / 1$. The differential count showed $65 \%$ blast cells, $5 \%$ segmented neutrophils, $25 \%$ lymphocytes, and $4 \%$ monocytes. The trephine biopsy showed replacement of normal elements with blast cells. Reticulin was moderately increased. The appearances were those of an acute leukaemic transformation of myelofibrosis.

Dapsone was added to the prednisone with no beneficial effect, and both the pyoderma gangrenosum and the leukaemia progressed rapidly. The patient had been unwilling to have a trial of chemotherapy and died of septicaemia shortly afterwards.

\section{Case 6}

A 19 year old woman attended the casualty section of Groote Schuur Hospital for a large necrotic ulcer on her right leg (Figure 1). She had no previous illness. On examination she was found to have a haemoglobin of $5 \mathrm{~g} / \mathrm{dl}$, given a blood transfusion, and, after dressing the wound, was discharged, to be followed as an outpatient. Three weeks later she re-presented with a fever of $38.5^{\circ} \mathrm{C}$ and was empirically treated with antibiotics. Dressings to the wound continued but this now measured $16 \mathrm{~cm} \times 12 \mathrm{~cm}$ and was noted to have a gangrenous centre. Blood count showed haemoglobin of $6 \mathrm{~g} / \mathrm{dl}$, total white blood count of $1.5 \times 10^{9} / 1$, with $7 \%$ neutrophils, $3 \%$ band forms, $1 \%$ eosinophils, $3 \%$ basophils, $70 \%$ lymphocytes, and $16 \%$ myeloblasts; platelet count was $60 \times 100^{9} / 1$. Bone marrow aspiration and trephine showed extensive replacement with 


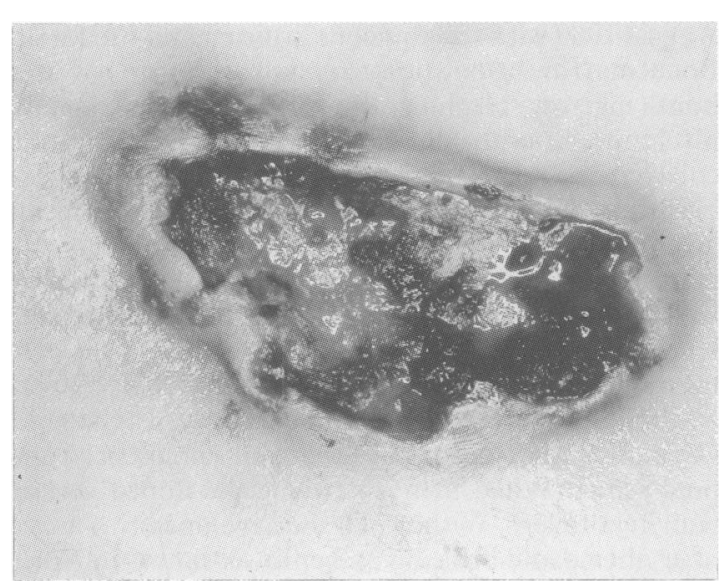

Figure 1 A large necrotic ulcer is seen on the right leg of the sixth patient. This was the presenting sign of her underlying leukaemia.

myeloblasts and a diagnosis of acute leukaemia was made. The patient achieved complete remission in response to cytosine arabinoside, doxorubicin, and VP16-213 (Jacobs et al., 1984), and after two courses of consolidation treatment entered a maintenance programme. The skin lesion healed completely, although slowly, over a period of 8 weeks (Figure 2) from commencing chemotherapy but recurred in the same site 16 months later when the patient relapsed. Further chemotherapy was unsuccessful and she eventually died from overwhelming sepsis.

\section{Discussion}

The pathogenesis of pyoderma gangrenosum is uncertain and circumstantial evidence suggests that it is a form of vasculitis (Allen \& Reeves, 1977).

In our patients, with the exception of the one having acute leukaemia who responded to chemotherapy, the lesions were extensive, often multiple, penetrated the deeper layers of the dermis, failed to heal, and were thought to be the site from which bacterial invasion eventually led to septicaemia and death of the 5 individuals. It is, however, noteworthy that in the sixth patient, although the lesion at first appeared to penetrate deeply into the dermis, slow but complete healing took place once remission had been induced with chemotherapy; eventually only an area of increased pigmentation remained. This latter experience would therefore be consistent with the suggestion that in haematological malignancy, despite initial and perhaps misleading appearances, more superficial ulceration may exist. It is not clear to what extent neutropenia or granulocyte dysfunction may decrease

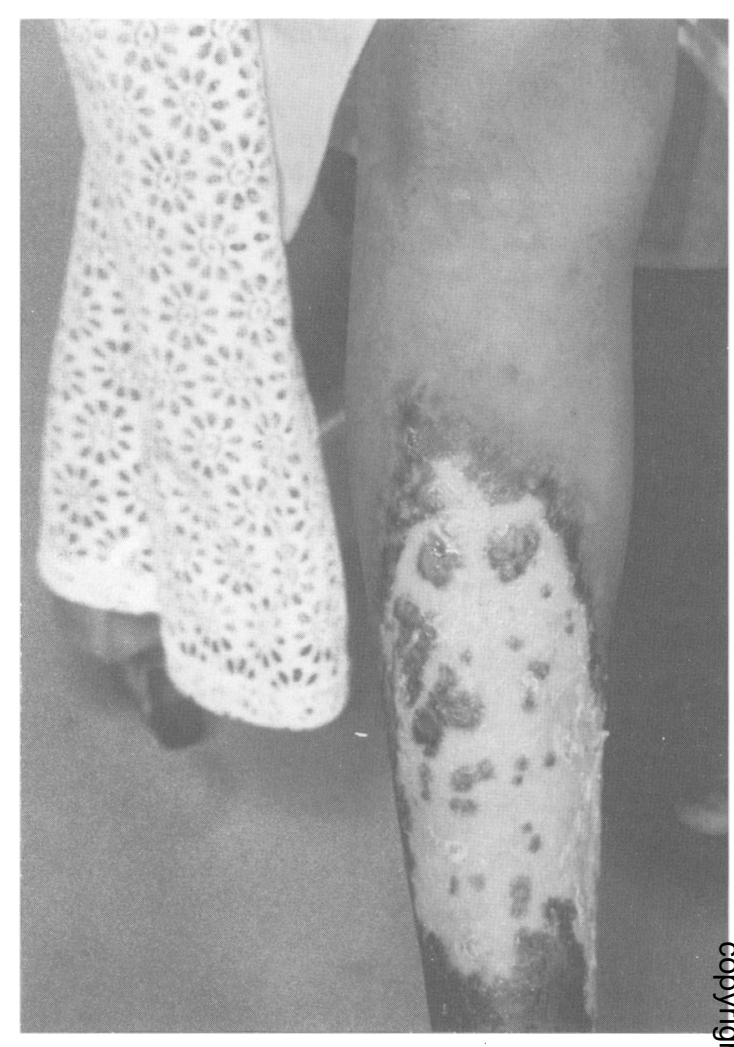

Figure 2 The eventual extent of the ulcer can be seen during the healing phase. The surprisingly good preservation of tissue is well demonstrated and eventually only an area of pigmentation remained.

leucocyte-mediated tissue destruction in these individuals.

The occurrence of pyoderma gangrenosum is recognized with acute and chronic leukaemia; both lymphoblastic and myeloblastic (Perry \& Winkelman, 1972; Lewis et al., 1978; Ortonne et al., 1979). However, its association with acute myeloproliferative disease (Toolis et al., 1978; Caughman et al., 1983) and the myelodysplastic or preleukaemic syndromes appears to have been less well described. The latter poses particularly difficult therapeutic challenges since the available evidence in rheumatoid arthritis and ulcerative colitis, as well as with our sixth patient, suggests that healing of the ulcer is only likely to occur once underlying disease has either been controlled or eradicated. In the latter group of patients treatment is not satisfactory and it remains to be seen whether the use of maturation-inducing agents such as low-dose cytosine arabinoside or administration of retinoids which, in laboratory culture systems may diminish proliferation and facilitate differentiation, will bring 
about comparable in vivo changes which may then allow tissue repair.

In more general terms, approaches to specific therapy have also been unrewarding. Systemic adrenocorticosteroids have produced rapid clinical improvement in many cases, particularly of inflammatory bowel disease and rheumatoid arthritis, where healing may reflect decreasing activity of the inflammatory process. Similarly, sulphone derivatives (Perry \& Winkelman, 1972), antimetabolites (Crawford et al., 1967; Maldonada et al., 1968) or clofazimine (Thomsen \& Rothenberg, 1979; Holt et al., 1980) may have an effect; here again, it is not clear whether benefit is related to the effect of the therapeutic agent on the ulcer or, as seems more probable, on the underlying disease, with spontaneous slow resolution of the skin lesion following thereafter. However, with clofazimine the enhanced intracellular killing of bacteria and increased phagocytosis of neutrophils shown in vitro and in vivo suggest an effect at cellular level, but the exact mechanism of action in this disease remains unknown. Swift healing of the lesions has also been reported (Lewis et al., 1978) in one leukaemic patient following commencement of cytosine arabinoside and daunorubicin therapy. The latter workers drew attention to one curious observation in their two patients where rapid resolution of previously extensive eryth- ema, oedema, and intense local tenderness followed excision of necrotic tissue in one and response in a single lesion following an extensive biopsy whilst others continued to enlarge.

It is concluded that pyoderma gangrenosum may occur with greater frequency than is generally appreciated in patients with acute and chronic leukaemia as well as in the myelodysplastic syndromes. Particularly in this latter group of individuals, an atypical form of the ulcers may exist with involvement of the more superficial layers of the skin and an unusual vesiculo-bullous border. Treatment remains unsatisfactory and is only likely to take place slowly and spontaneously with induction of complete remission in acute leukaemia; the possibility that a similar response may follow the use of maturation-inducing agents in the myelodysplastic syndrome remains speculative.

\section{Acknowledgements}

Supported by the University of Cape Town Leukaemia Centre and Staff Research Fund, the Medical Research Council and National Cancer Institute. We thank Jackie Davies for secretarial assistance and the Medical Superintendent of Groote Schuur Hospital for permission to publish.

\section{References}

ALLEN, B.R. \& REEVES, W.G. (1977). Skin disease. In Immunology in Medicine. A Comprehensive Guide to Clinical Immunology. Holborow, E.J. \& Reeves, W.G., (Eds) pp. 814-815. Academic Press: London.

BRUNSTING, L.A., GOECKERMAN, W.H. \& O'LEARY, P.A. (1930). Pyoderma (echthyma) gangrenosum: clinical and experimental observation in five cases occurring in adults. Archives of Dermatology and Syphilology, 22, 655.

CAUGHMAN, W., STERN, R. \& HAYNES, H. (1983). Neutrophilic dermatosis of myeloproliferative disorders. Atypical forms of pyoderma gangrenosum and Sweet's syndrome associated with meloproliferative disorders. Journal of the American Academy of Dermatology, 9, 751.

CRAWFORD, S.E., SHERMAN, R. \& FAVARA, B. (1967). Pyoderma gangrenosum with response to cyclophosphamide therapy. Journal of Pediatrics, 71, 255.

FAYOLle, J., ENAY, G. \& WOEHRIE, R. (1974). Pyoderma gangrenosum et leucose aigue myeloblastique: Cas personnel et revue de la literature. Lyon Médical, 232, 85.

GOLDIN, D. (1974). Pyoderma gangrenosum with chronic myeloid leukaemia. Proceedings of the Royal Society of Medicine, 67, 1239.

HOLT, P.J., DAVIES, M.G., SAUNDERS, K.C. \& NUKI, G. (1980). Pyoderma gangrenosum: clinical and laboratory findings in 15 patients with special reference to polyarthritis. Medicine (Baltimore), 59, 114.

JACOBS, P., DUBOVSKY, D.W. \& WOOD, L. (1984). In adult acute nonlymphoblastic leukaemia extended maintenance chemotherapy has no benefit. American Journal of Hematology, 16, 255.

LEWIS, S.J., POH-FITZPATRICK, M.B. \& WALTHER, R.R. (1978). Atypical pyoderma gangrenosum with leukemia. Journal of the American Medical Association, 239, 935.

MALDONADA, N., TORRES, V., MENDEZ-CASHION, D., PEREZ-SANTIAGO, E. \& DE COSTA, M.C. (1968). Pyoderma gangrenosum treated with 6-mercaptopurine and followed by acute leukaemia. Journal of Pediatrics, 72, 409.

ORTONNE, J.P., THIVOLET, J., CHOUVET, B. \& COIFFET, J. (1979). Pyoderma gangrensum, ovarian carcinoma treated with melphalan and acute myelomonocytic leukaemia: report of one case and literature review (Fren). Anales de Dermatologie et de Venereologie, 106, 251.

PERRY, H.O. \& BRUNSTING, L.A. (1957). Pyoderma gangrenosum: a clinical study of nineteen cases. Archives of Dermatology 75, 380.

PERRY, H.O. \& WINKELMANN, R.K. (1972). Bullous pyoderma gangrenosum and leukaemia. Archives of Dermatology, 106, 901.

SLOAN, W.P., BARGEN, J.A. \& GAGE, R.P. (1950). Life histories of patients with chronic ulcerative colitiv: A review of 2000 cases. Gastroenterology, 16, 25.

STOLMAN, L.P., ROSENTHAL, D., YAWORSKY, R. \& HORAN, F. (1975). Pyoderma gangrenosum and rheumatoid arthritis. Archives of Dermatology, 111, 1020.

TAY, C.A. (1973). Pyoderma gangrenosum and leukemia. 
Archives of Dermatology, 108, 580.

THOMSEN, K.\& ROTHENBORG, H.W. (1979). Clofazimine in the treatment of pyoderma gangrenosum. Archives of Dermatology, 115, 851.

TOOLIS, F., PARKER, A.C. \& BARNETSON, R. (1978). Pyoderma gangrenosum associated with acute myeloproliferative dissease (?erythroleukaemia). Postgraduate Medicine, 54, 830.

WOLFF, K. \& STINGL, G.(1983). Pyoderma gangrenosum. In Dermatology in General Medicine, pp. 174-183. Fitzpatrick, T.B., Arndt, K.A., Clark, W.H., van Scott, E.J. \& Vaughan. J.H. (eds). McGraw-Hill: New York. 